\title{
Membrane formation in the chamber angle after failure of argon laser trabeculoplasty: analysis of risk factors
}

\author{
T Koller, J Stürmer, Ch Remé, B Gloor
}

\section{Augenklinik, UniversitätsSpital, Zürich, Switzerland T Koller J Stürmer Ch Remé B Gloor \\ Correspondence to: Dr J Stürmer, Augenklinik, Nordtrakt II, \\ UniversitätsSpital, \\ Frauenklinikstrasse 24, CH-8091 Zürich, Switzerland \\ Accepted for publication 18 August 1999}

Figure 1 Low power light micrograph depicting a normal chamber angle region. Schlemm's canal (S), the trabecular meshwork (T), parts of the ciliary muscle $(C)$, and the iris (I). Original magnification $\times 10$.

Conclusions-Membrane formation in the chamber angle is a frequent cause of ALT failure. The major risk factor is the number of ALTs performed.

(Br f Ophthalmol 2000;84:48-53)

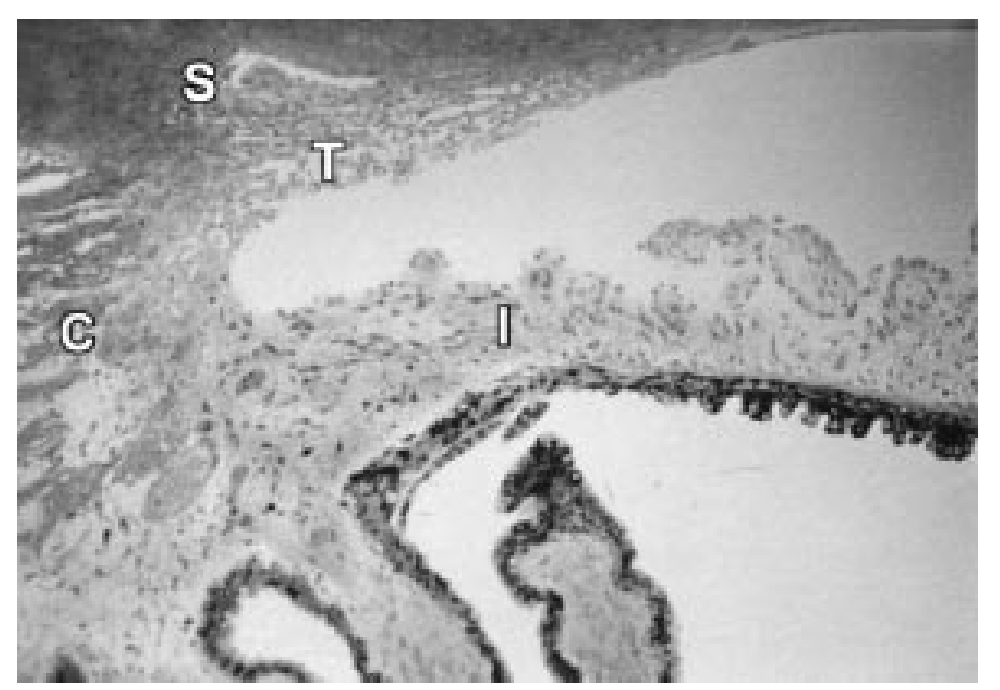

\begin{abstract}
Aim-Membrane formation in the chamber angle induced by argon laser trabeculoplasty (ALT) can be a cause of treatment failure. Identification of risk factors for membrane formation was the primary aim of this retrospective study.

Methods-Semithin sections of trabeculectomy specimens obtained in a 2 year period were examined by light microscopy. 122 eyes which were treated with one or more ALTs before trabeculectomy were identified. In 46 eyes, a sufficient amount of trabecular meshwork was obtained to permit morphological analysis.

Results-Eyes treated with ALT had a significantly higher incidence of membrane formation $(p=0.001)$. In $23 / 46$ specimens a cellular and collagenous membrane was observed covering the entire trabecular meshwork. In $14 / 23$ specimens (61\%), this membrane was readily visible at low power magnification $(\times 40)$. Comparison of these eyes with those without membrane formation revealed a significant difference in the number of ALTs (mean 2.07 (SD 0.73) $v 1.48(0.59) ; \mathrm{p}=0.026)$ and in preoperative IOP $(32.0(9.7) v 26.2(8.4) \mathrm{mm}$ Hg; p= 0.04).
\end{abstract}

Since the introduction of argon laser trabeculoplasty (ALT) in 1979 by Wise and Witter ${ }^{1}$ it has become one of the standard treatments for glaucoma. Recent reports, however, reveal a failure rate of $15-25 \%$ in the first year and annual failure rates of $5-10 \%$ thereafter. Within 10 years most patients (68-95\%) fail ${ }^{2-5}$ and require further intervention. Since 1973, we have gathered trabeculectomy specimens in order to determine if intraocular pressure (IOP) regulation is dependent on the anatomical site of excision, specifically comparing excisions that were fashioned in proximity to the cornea with those more peripherally based to include uveal tissue and scleral spur. More recently, we have seen repeat ALT treated patients with acutely elevated IOP in the $50 \mathrm{~s}$, despite intensive medical therapy, who required emergency trabeculectomy. We investigated a possible cause of such a pressure rise by more closely examining trabeculectomy specimens using light and electron microscopy. In many specimens we found a significant membrane covering the trabecular meshwork. ${ }^{6}$ The aim of this retrospective study was to find out if there is any relation between membrane formation, pressure elevation, and previous ALT.

\section{Material and methods}

Over a period of 2 years, 388 eyes of 290 patients underwent filtering surgery at our department. A standard trabeculectomy with a fornix based conjunctival flap was performed. The inner block of tissue at the trabeculectomy site was excised using a diamond knife and straight corneal scissors. Immediately after excision, the tissues were immersed in fixative consisting of $2.5 \%$ glutaraldehyde in $0.1 \mathrm{M}$ cacodylate buffer, $\mathrm{pH}$ 7.3. The tissues remained in this fixative for 12 hours at $4^{\circ} \mathrm{C}$. They were then postfixed in osmium tetroxide for 1 hour, gently dehydrated and embedded in Epon 812 . Sections of $0.5 \mu \mathrm{m}$ were cut, stained with methylene blue, and observed with Zeiss Axiophot. Thin sections were cut, stained with uranyl acetate and lead citrate, and observed with a Hitachi 7000 transmission electron microscope. Tissues were oriented so that sagittal sections through the trabecular region were cut (Fig 1).

Of these 388 eyes 122 had one or more previous argon laser trabeculoplasties. We selected only those specimens in which all important structures (that is, Schwalbe's line, canal of Schlemm, trabecular meshwork) were visible and only one eye per patient was evaluated. This resulted in 54 specimens assigned to the 


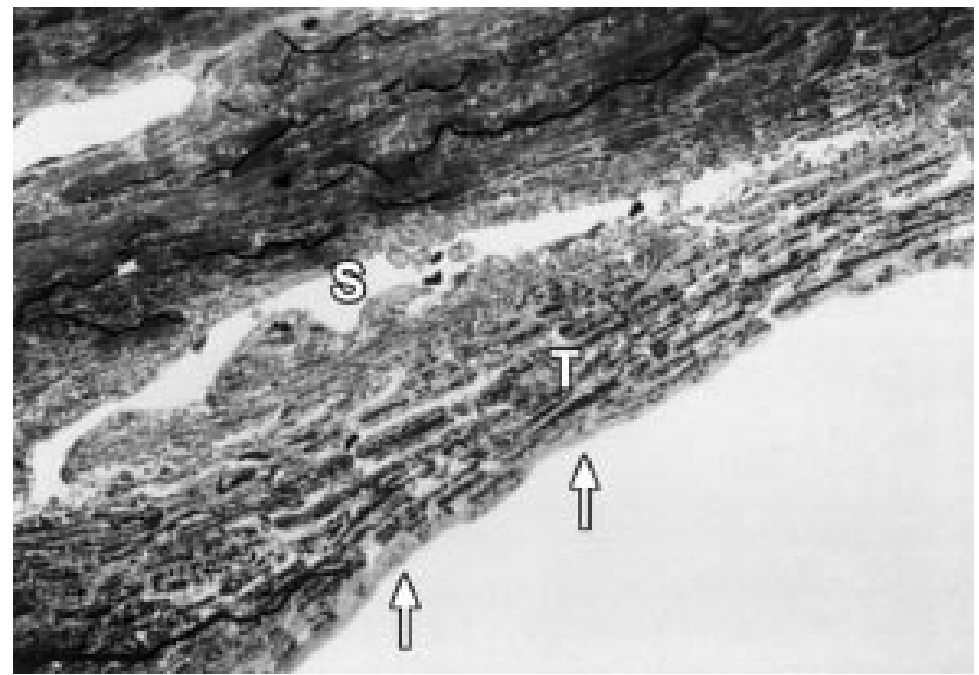

Figure 2 Light micrograph showing the Schlemm's canal (S) and the trabecular meshwork (T). A membrane (arrows) extends over the meshwork, intertrabecular spaces are narrow. Original magnification $\times 40$.

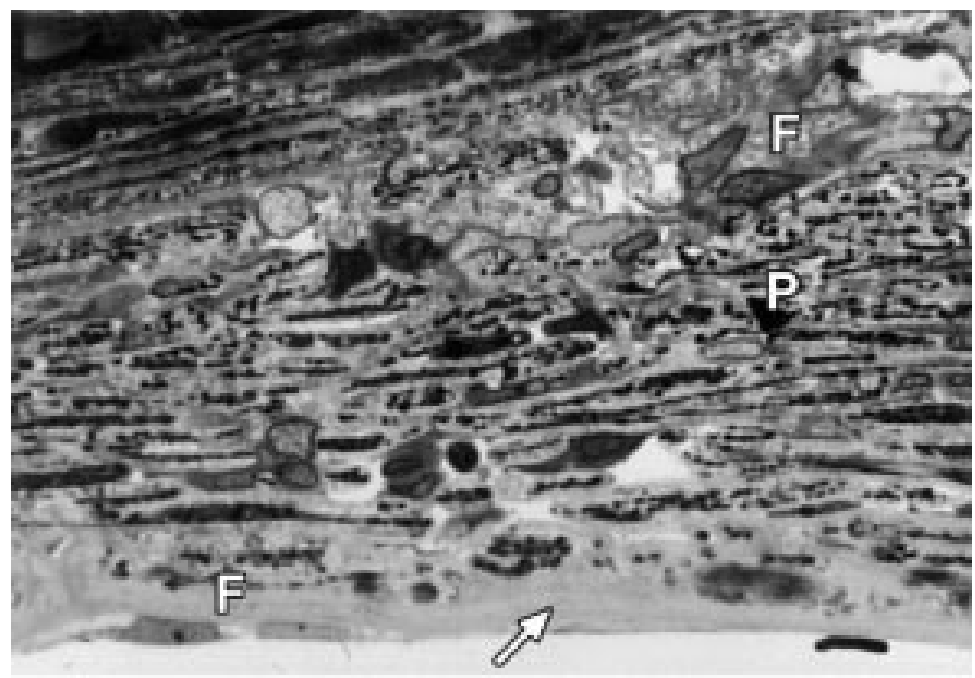

Figure 3 High power light micrograph illustrating a distinct membrane (arrow) extending over the trabecular meshwork. The intertrabecular spaces are obliterated, large fibrocytic cells $(F)$ and pigment granules $(P)$ appear within the meshwork. Original magnification $\times 100$.

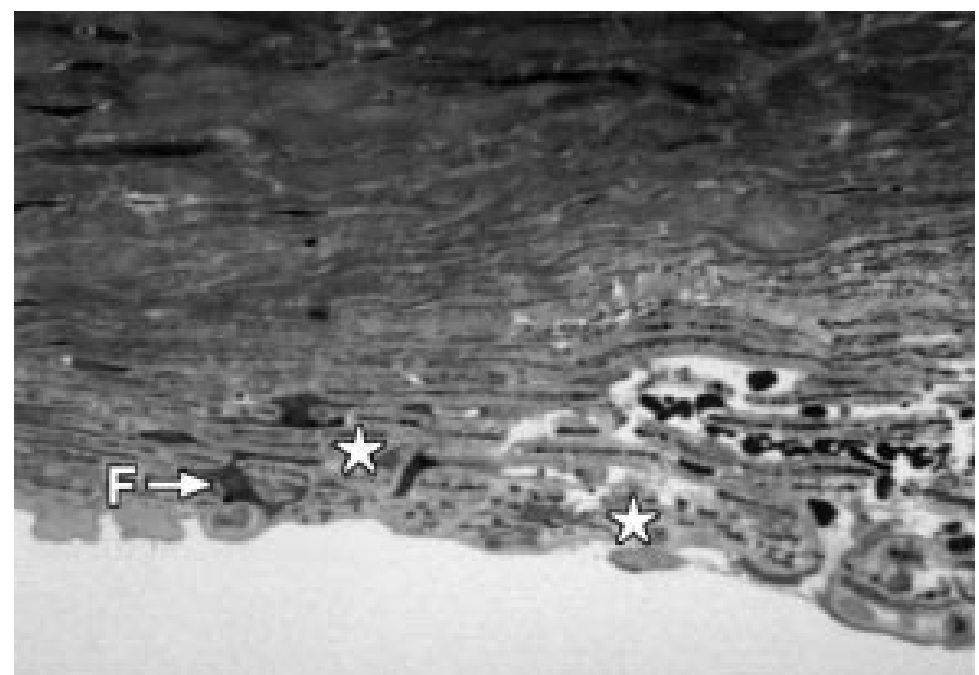

Figure 4 Light micrograph showing the region of Schwalbe's line and the anterior trabecular meshwork. Newly formed collagen ( $\left.{ }^{\star}\right)$ and fibrocytic cells $(F)$ are seen. Original magnification $\times 100$.
ALT group. The control group consisted of 64 eyes not previously treated with ALT. These eyes were randomly selected from the 266 eyes without previous ALT and had similar diagnoses, age, and sex distribution as the ALT group. Because we expected to find more membranes in patients with previous ALT, we further analysed patients with primary open angle glaucoma with previous laser treatment. Only POAG was taken into consideration and patients were divided into two groups, those with ( $\mathrm{n}=23$ ) and without ( $\mathrm{n}=23$ ) membrane formation. Diagnosis, age, IOP before and after ALT, total energy and number of laser shots applied, number of ALTs performed, interval between last ALT and surgery, as well as IOP and number of topical medications before surgery were assessed as possible risk factors leading to membrane formation. Unfortunately we could not collect data about the prelaser pigmentation of the trabecular meshwork.

\section{Results}

A membrane over the trabecular meshwork was noted in many specimens. Membranes visible under low power magnification $(\times 40)$, were referred to in this study as thick (Fig 2), whereas those membranes visible under higher magnification $(\times 100)$ were referred to as thin (Fig 3). Using electron microscopy, a dense structure over the trabecular meshwork as well as a substance in the intertrabecular spaces was observed. Anticipating that this could be early membrane formation, the production of collagen was assessed both in the region of Schwalbe's line and in the anterior trabecular meshwork (Figs 4 and 5). The trabecular meshwork was further found to contain exfoliative material, pigment granules, or endothelial cells. In sections viewed under light microscopy, the membranous material was seen covering Schwalbe's line, the corneal meshwork, and in some instances the entire corneal and uveal meshwork. Trabecular endothelial cells appeared to be active demonstrating prominent nucleoli and migration activity. Intracellular and extracellular pigment granules were often prominent. In electron microscopy sections (Fig 6), the membranous material was found to consist of islands of newly formed collagen fibres and irregular, densely packed larger fibrils. In several specimens long spacing collagen was visible in the anterior corneal meshwork. Macrophages were apparent in the trabecular meshwork and in the region of Schwalbe's line (data not shown). Trabecular endothelial cells also showed phagocytic activity with pigment granules within their cytoplasm. Fibroblast-like cells containing dilated cisterns of rough endoplasmic reticulum were apparent in the trabecular meshwork and along Schwalbe's line. In specimens of patients with pseudoexfoliation syndrome (PEX), exfoliative material was distinctly visible in the trabecular meshwork and the canal of Schlemm. Similarly, this material was found lining the walls of the collector channels. These findings were supported by the presence of exfoliative material in the iris 


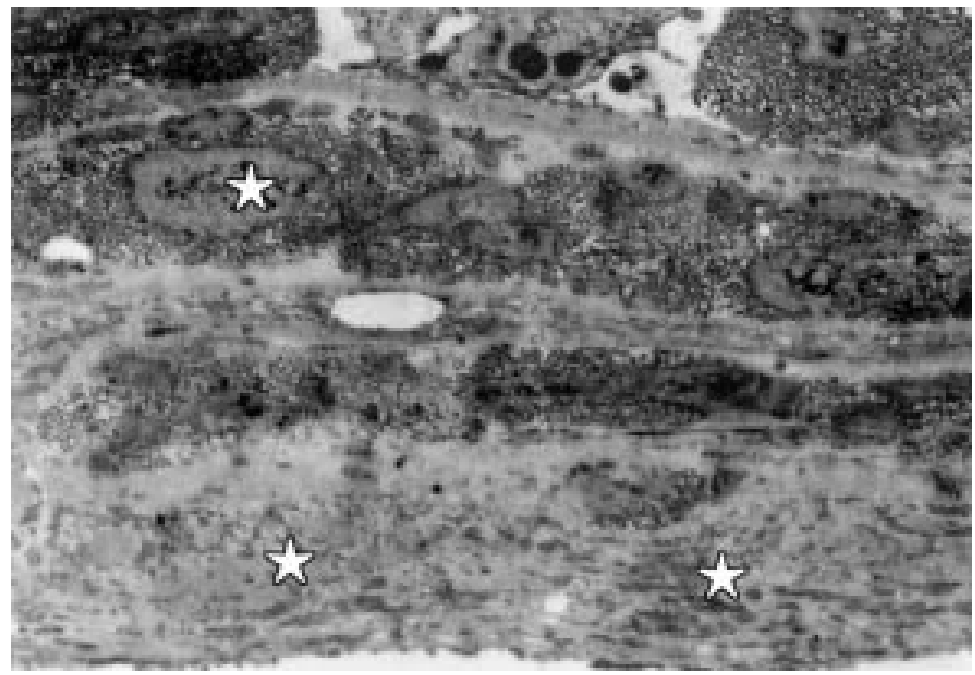

Figure 5 Electron micrograph showing newly formed collagen fibrils ( $\left.{ }^{\star}\right)$ in the region of the membrane covering the trabecular meshwork. Original magnification $\times 10000$.

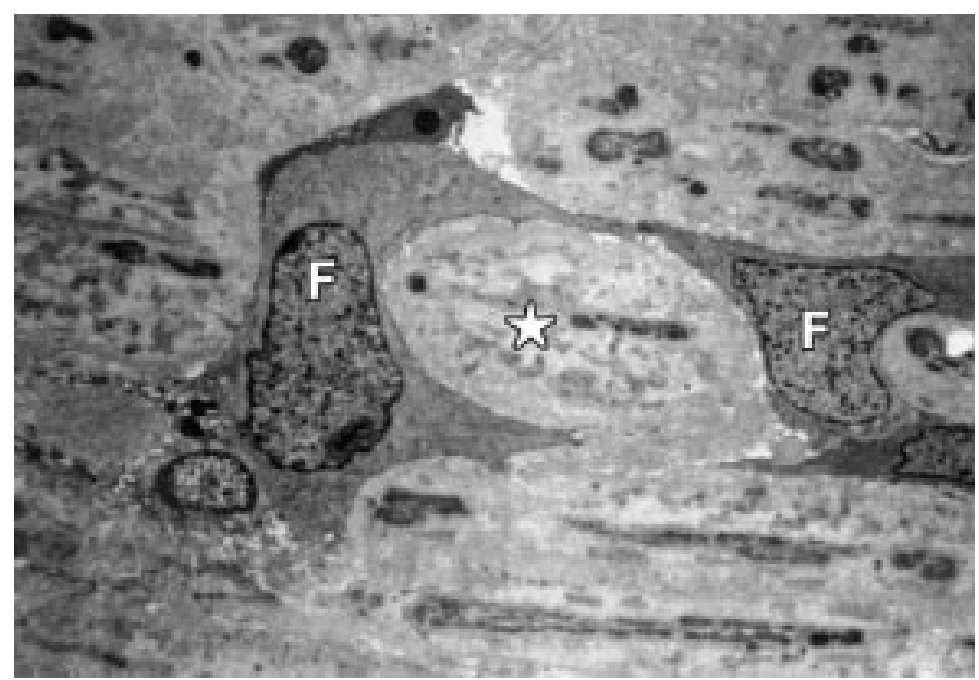

Figure 6 Electron micrograph demonstrating collagen formation $\left(^{\star}\right)$ in the anterior meshwork area. $F=$ activated fibrocyst. Original magnification $\times 5000$.

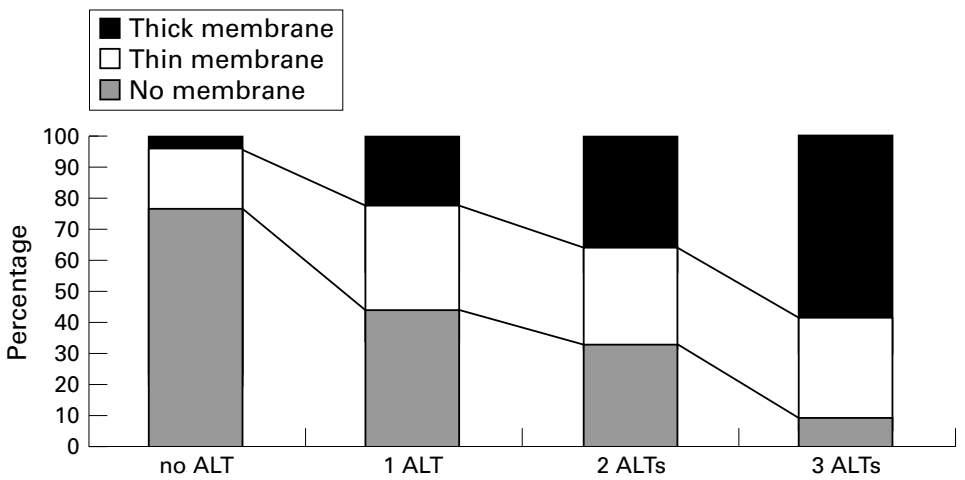

Figure 7 Membrane formation and ALT.

Table 1 Eyes with ALT have longer topical therapy and develop more Tenon cysts (both significant, $p<0.001$ )

\begin{tabular}{lclc}
\hline & Topical therapy & Medicaments & $\begin{array}{c}\text { Postoperative } \\
\text { Tenon cyst }\end{array}$ \\
\hline No ALT (n=64) (SD) & $7.05(26.5)$ minutes & $2.24(0.88)$ & $3.10 \%$ \\
With ALT (n=54) (SD) & $49.58(30.07)$ minutes & $2.36(0.85)$ & $24.07 \%$ \\
$t$ test & $<0.001$ & 0.45 & $<0.001$ \\
\hline
\end{tabular}

stroma and on the posterior surface of iridectomy specimens.

Results of the first study group, which compared ALT treated eyes with untreated controls, suggested that each additional laser intervention increased the incidence of membrane formation (Fig 7). Moreover, patients treated with ALT were managed with topical therapy for longer than controls before surgery and had developed significantly more Tenon cysts following trabeculectomy (Table 1). Statistical comparison of the histological findings revealed significantly more frequent membrane formation after argon laser trabeculoplasty $\left(\mathrm{p}<0.001, \chi^{2}\right.$ test, Fig 8). Furthermore, there was a weak correlation for membrane formation in PEX $(p=0.11)$, but the statistical correlation is artificial, because there were more PEX patients in the ALT group. There was no difference in the frequency of collagen formation $(p=0.16)$, in the amount of pigment granules $(p=0.88)$, and endothelial cells $(p=0.47)$ in the trabecular meshwork between the compared groups with and without ALT.

The second study group compared 23 eyes with membranes to 23 eyes without membranes in order to ascertain retrospectively which specific risk factors may contribute to the development of a membrane across the chamber angle. Older age was found to be weakly associated with membrane formation ( $\mathrm{p}=0.114$, Mann-Whitney U test). Particular attention was given to patients who had been treated with argon laser trabeculoplasty (Table 2 ). There was a significant difference in the number of ALTs performed on eyes with a thick membrane and those with absent membranes: thick membranes were associated with eyes that had received a greater number of ALTs $(p=0.026)$. A similar association was seen with eyes having a membrane only visible with electron microscopy $(\mathrm{p}=0.124)$ and also with eyes having a thin membrane $(p=0.06)$. Patients with thick membranes had a significantly $(p=0.04)$ higher IOP before filtering surgery than patients without membranes. Furthermore, preoperative IOP was higher in those patients with a thick membrane compared with those with a thin membrane $(p=0.055)$. A significantly higher total energy $(p=0.04)$ and total number of laser shots $(p=0.035)$ had been applied to patients with thick membranes in comparison to those with thin membranes. Patients with thick membranes in the chamber angle required more $(\mathrm{p}=0.022)$ systemic carbonic anhydrase inhibitor therapy preoperatively than those without membranes. In fact, any degree of membrane formation showed a tendency to require more intensive topical therapy preoperatively $(\mathrm{p}=0.077)$.

Only 12 of 64 eyes without ALT had membranes in the chamber angle (Table 3). This finding suggests that other procedures such as surgical iridectomy, Nd:YAG iridotomy, lens extraction, and cyclocryotherapy may also induce membrane production in the chamber angle. Secondary glaucomas, which were prevalent in the untreated group, may also be implicated as a causative factor. 


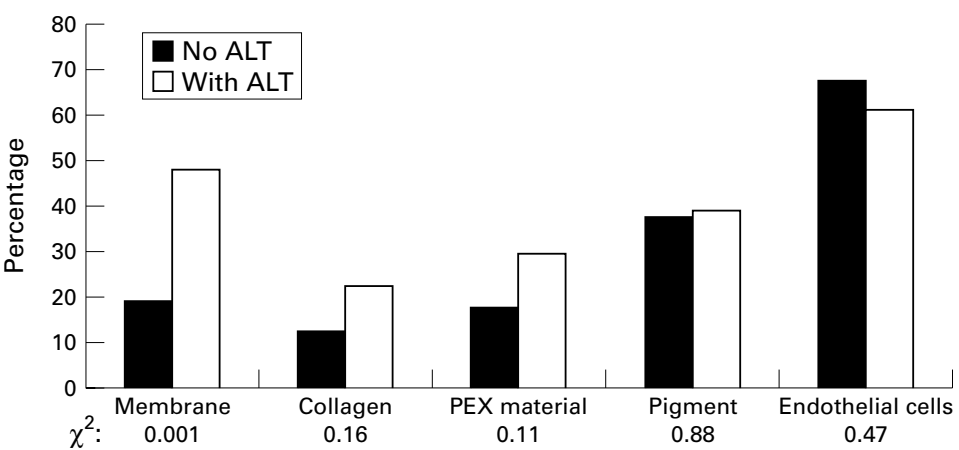

Figure 8 Histology. Membrane formation, collagen fibrils, pseudoexfoliative material, amount of pigment, and endothelial cells in the trabecular meshwork compared in eyes with and without ALT. Eyes with ALT have significantly more membranes over the trabecular meshwork $(p=0.001)$ than eyes without.

\section{Discussion}

MORPHOLOGICAL FINDINGS IN THE CHAMBER ANGLE AFTER LASER TREATMENT

In enucleated eyes previously treated with argon laser trabeculoplasty Alexander and colleagues $^{7}{ }^{8}$ observed distortion of trabecular beams, loss of trabecular endothelial cells, and the development of a cellular sheet extending from Schwalbe's line to the anterior portion of the uveal meshwork. Similar morphological changes were noted in this study (Figs 5 and 6) which were interpreted as the early formation of a membrane. ${ }^{69}$ Rodrigues et al ${ }^{10}$ found an occlusion of the intertrabecular space by corneal and trabecular endothelial cells whereas others ${ }^{11}$ described a widening of the intertrabecular spaces by direct traction on the trabecular meshwork by the photocoagulated tissues. In light microscopic and immunohistological studies Babizhayev et al ${ }^{12}$ reported very similar findings: partial or total occlusion of the intertrabecular spaces by extracellular debris, evidence of heat effects with disruption, and shrinkage of the trabecular meshwork and accumulation of fibronectin deposits in the aqueous drainage channels.

Melamed et al, ${ }^{13-15}$ Koss et al, ${ }^{16}$ and Alvarado et $a l^{17}$ reported laser induced changes in eyes of cynomolgus monkeys. Koss et $a l^{16}$ found a statistically significant increase in aqueous humour protein concentration and fibrinous material covering the trabecular channels 4 hours after ALT. Alvarado ${ }^{17}$ induced glaucoma by intensive laser treatment and noticed a cell layer over the trabecular meshwork which significantly reduced the flow through the chamber angle and induced an intraocular pressure rise. Melamed et $a l^{13-15}$ demonstrated an impermeability to aqueous humour flow through the actual lasered lesions. Adjacent non-lasered spots had wide open intertrabecular spaces with herniations of juxtacanalicular trabecular meshwork and of inner wall endothelium into and across the lumen of Schlemm's canal. The herniations contained inflammatory cells which were actively phagocytic.

These reports are supported by findings of intense scar formation in cultures of trabecular cells treated with laser. ${ }^{18}{ }^{19}$ The morphology of specimens ${ }^{6}$ in the current study are similar to those described above. All investigators report an inflammatory reaction after ALT with activated fibroblasts, collagen production, and possible scar formation in the chamber angle.

\section{PRESSURE RISE AFTER ARGON LASER}

\section{TRABECULOPLASTY}

One of the most frequent postoperative complications after ALT is a rise in intraocular pressure. Many of our patients developed pressure spikes requiring emergency trabeculectomy. Pigmentation of the trabecular meshwork and posterior placement of laser burns seems to be strongly associated with an increase in intraocular pressure. ${ }^{20}{ }^{21}$ This oc-

Table 2 Patients who had been treated with argon laser trabeculoplasty

\begin{tabular}{|c|c|c|c|c|}
\hline & No membrane & With membrane & Thin membrane & Thick membrane \\
\hline Number & 23 & 23 & 9 & 14 \\
\hline Age & $68.1(14)$ & $74.5(9.7)$ & $76(4.4)$ & $73.5(12)$ \\
\hline No of ALTs & $1.48(0.59)$ & $1.83(0.72)$ & $1.44(0.53)$ & $2.07(0.73)$ \\
\hline IOP before TE & $26.2(8.4)$ & $28.7(9.6)$ & $23.7(7.3)$ & $32(9.7)$ \\
\hline Total energy $(J)$ & $9.6(4.72)$ & $9.9(5.67)$ & $7.3(5.1)$ & $11.7(5.5)$ \\
\hline Total number of laser shots & $93.4(48.3)$ & $99.6(50.2)$ & $71.6(27.1)$ & $119(54.1)$ \\
\hline Carboanhydrase inhibitors & $6 / 23(26.1 \%)$ & $13 / 23(56.5 \%)$ & $3 / 9(33 \%)$ & $10 / 14(71.4 \%)$ \\
\hline \multicolumn{5}{|l|}{ Mean (SD) } \\
\hline \multicolumn{5}{|c|}{ Total energy $=\mathrm{W} \times$ time $\times$ number of laser shots $=\mathrm{J}$} \\
\hline \multicolumn{5}{|c|}{ Comparison of patients with and without membrane } \\
\hline Age & $\mathrm{p}=0.114$ & ns & & \\
\hline No of ALTs & $\mathrm{p}=0.124$ & ns & & \\
\hline Preoperative use of carboanhydrase inhibitors & $\mathrm{p}=0.077$ & ns & & \\
\hline \multicolumn{5}{|c|}{ Comparison of patients with thick membrane and without membrane } \\
\hline No of ALTs & $\mathrm{p}=0.026$ & $\mathrm{~s}$ & & \\
\hline IOP before trabeculectomy & $\mathrm{p}=0.04$ & $\mathrm{~s}$ & & \\
\hline Preoperative use of carboanhydrase inhibitors & $\mathrm{p}=0.022$ & s & & \\
\hline \multicolumn{5}{|c|}{ Comparison of patients with thick and with thin membrane } \\
\hline No of ALTs & $\mathrm{p}=0.06$ & ns & & \\
\hline IOP before trabeculectomy & $\mathrm{p}=0.055$ & ns & & \\
\hline Total energy $(J)$ & $\mathrm{p}=0.04$ & $\mathrm{~s}$ & & \\
\hline No of laser shots & $\mathrm{p}=0.35$ & s & & \\
\hline
\end{tabular}

ns = not significant; $\mathrm{s}=$ significant.

Eyes with thick membranes had significant more ALTs $(p=0.026)$, a higher IOP $(p=0.04)$, and more carboanhydrase inhibitors $(\mathrm{p}=0.022)$ preoperatively than eyes without membrane formation over the trabecular meshwork.

Eyes with thick membranes received more energy $(p=0.04)$ and more laser shots $(p=0.035)$ on the trabecular meshwork compared with patients with thin membrane formation. 
Table 3 Patients with membrane formation without previous argon laser trabeculoplasty

\begin{tabular}{llll}
\hline & Diagnosis & Age & Other clinical findings \\
\hline$(1)$ & POAG & 62 & \\
$(2)$ & POAG & 77 & \\
$(3)$ & POAG & 75 & Myopia (-9.75D) \\
$(4)$ & POAG & 67 & Horner syndrome \\
$(5)$ & POAG & 79 & Malignant melanoma \\
$(6)$ & POAG & 77 & Pseudophakia (posterior chamber \\
$(7)$ & POAG & 77 & \\
& & & \\
$(8)$ & PEX & 68 & YAG iridotomy synechiae \\
$(9)$ & PEX & 56 & Sinus cavernosus syndrome \\
$(10)$ & CACG & 72 & Heterochromic cyclitis, aphakia, \\
$(11)$ & Uveitic glaucoma & 66 & pars plana vitrectomy, \\
$(12)$ & Uveitic glaucoma & 48 & cyclocryocoagulation, YAG \\
& & & \\
& & & \\
\end{tabular}

currence could be a consequence of an inflammatory response within the trabecular meshwork. In $100 \%$ of PDS, in $69-75 \%$ of PEX and in $25 \%$ of the POAGs a prostaglandin triggered inflammation of the chamber angle structures ${ }^{2021}$ has been reported, which directly correlates with the postoperative pressure rise. A pressure spike following a single ALT is very likely to result in an even higher pressure rise after subsequent ALTs. ${ }^{22}$ The same inflammatory mechanism can also lead to peripheral anterior synechiae formation. All of these sequelae in the early post-ALT period could be explained by obstruction of the intertrabecular spaces by debris or endothelial cells or by an inflammatory response which later leads to membrane formation. This reaction could be reduced by application of NSAID. Huk et $a l^{23}$ reported a significant reduction in protein concentration and inflammatory response within the anterior chamber after use of NSAID.

THERAPEUTIC MANAGEMENT AND CLINICAL

BEHAVIOUR

Hugkulstone et $a l^{24-26}$ compared 0.1 and 0.2 second duration argon laser trabeculoplasty. A duration of 0.2 second resulted in the greatest drop in IOP with patients requiring fewer topical medications and fewer subsequent interventions. These same patients, however, reported more discomfort with the procedure. One patient developed a pressure spike requiring filtration surgery 1 month post-ALT. This failure of IOP control could be the result of total or partial occlusion of the trabecular meshwork by membrane formation or intertrabecular debris as a consequence of laser treatment that was too intense. Wise and Witter ${ }^{1}$ proposed energy levels between 0.1 and $0.5 \mathrm{~W}$. Some authors ${ }^{22}{ }^{27}{ }^{28}$ did not observe any correlation between energy level and clinical response. Rouhiainen and colleagues ${ }^{29}{ }^{30} \mathrm{ex}-$ perimented with energy levels much lower than those proposed by Wise and Witter. They reported relatively low success rates $(33 \%)$. These authors ${ }^{31}$ also examined three groups with $0.5,0.7$, and $0.9 \mathrm{~W}$ ALTs. Most of the significant IOP increases were in the high power group and the average postoperative IOP increase was also greatest in this group. Other investigators ${ }^{32-35}$ compared $180^{\circ}$ and $360^{\circ}$ ALT. In the group receiving $180^{\circ}$ ALT the post-treatment complications (iritis, cor- neal opacities, transient hypertension, anterior peripheral synechiae) were less frequent and less severe. The greatest rise in postoperative IOP was found in the $360^{\circ} \mathrm{ALT}$ group and one of these patients had marked loss of visual field within 24 hours. Takenaka et $a l^{36}$ had found similar results after $180^{\circ}$ and one quadrant ALT. Repeat ALT seems to be effective in only $25 \%$ to $32 \%{ }^{28}{ }^{37}$ Better success rates are reported in patients who had a prolonged favourable response to their initial treatment. ${ }^{38}$ Early failure seems to produce an unfavourable outcome with repeat treatment. ${ }^{22}$ Brown et al and Schoenleber et $a l^{39}{ }^{40}$ studied patients requiring repeat ALT. About every seventh patient had a marked increase in IOP, necessitating urgent surgical intervention. As previously described, ${ }^{37}{ }^{41-45}$ an increased incidence of postoperative Tenon cysts was observed following repeat ALT in this study. Perhaps this occurs because an inflammatory cascade is triggered by the ALT which leads to scar formation at the surgical wound.

\section{Summary}

The thickness of a membrane covering the chamber angle seems to be correlated with the number of ALTs performed. More than two argon laser trabeculoplasties (involving over $360^{\circ}$ ) may induce the formation of such a membrane which is strongly associated with higher preoperative IOP and hypertensive crisis. $^{6}{ }^{1635}$ Because Migdal et al ${ }^{46}$ revealed a slightly better long term IOP reduction after primary trabeculectomy compared with argon laser trabeculoplasty, we suggest that, although ALT may be a successful treatment modality in various forms of open angle glaucoma, it should be restricted to cases in which gaining time is desirable. Examples include the elderly and patients whose way of life could deteriorate following trabeculectomy, such as a one eyed patient who develops a secondary cataract. In patients who will inevitably end up with trabeculectomy, ${ }^{40}$ ALT could result in a loss of time and loss of additional ganglion cells, if one only considers increased excavation, decreased rim and field change as criteria to change treatment modalities. These dangers of ALT brought Alvarado ${ }^{17}$ to proclaim: "There is a narrow margin between the beneficial and the deleterious effects of argon laser trabeculoplasty to the trabecular meshwork."

\footnotetext{
1 Wise JB, Witter SL. Argon laser therapy for open-angle glaucoma: a pilot study. 7 Glaucoma 1979;2:7-12.

2 Johnson DH, Yoshikawa K, Brubaker RF, et al. The effect of long-term medical therapy on the outcome of filtration surgery. Am f Ophthalmol 1994;117:139-48.

3 Ritch R, Liebmann J, Robin A, et al. Argon laser trabeculoplasty in pigmentary glaucoma. Ophthalmology 1993;100 909-13.

4 Shingleton BJ, Richter CU, Dharma SK, et al. Long-term efficacy of argon laser trabeculoplasty. Ophthalmology 1993;100:1324-9.

5 Spaeth GL, Baez KA. Argon laser trabeculoplasty controls one third of cases of progressive, uncontroled open angle glaucoma for 5 years. Arch Ophthalmol 1992;110:491-4.

6 Federspiel E, Remé Ch, Gloor B, et al. Why do some argonlaser trabeculoplasties fail. Laser Ophthalmol 1987;14:191-6.

7 Alexander RA, Grierson I, Church WH. The effect of argon exander RA, Grierson I, Church WH. The effect of argon laser trabeculoplasty upon the normal human trabecular

meshwork. Graefes Arch Clin Exp Ophthalmol 1989;227:72-7.

8 Alexander RA, Grierson I. Morphological effects of argon laser trabeculoplasty upon the glaucomatous meshwork
Eye 1989;3:719-26.
} 
9 Stürmer J, Meier-Gibbons F, Clausen M, et al. Cell proliferation and membrane formation concomitant with proliferation and membrane formation concomitant with
extreme intraocular pressure increase following argon laser extreme intraocular pressure increase following argon laser
trabeculoplasty. Krieglstein GK (Hrsg) Glaucoma update Vol trabeculoplasty. Krieglstein GK (Hrsg)
V,1. Heidelberg: Aufl Kaden, 321-30.

10 Rodrigues MM, Spaeth GL, Donohoo P. Electron microscopy of argon laser therapy in phakic open-angle glaucoma Ophthalmology 1982;26:1336-42.

11 De-Concini M, Boi S, Detassis C. Microscopical study of trabeculum after laser cyclotrabeculospasis: case report Pathologica 1993;85:563-7.

12 Babizhayev MA, Brodskaya MW, Mamedov NG, et al. Clinical, structural and molecular phototherapy effects of laser irradiation on the trabecular meshwork of human glaucomatous eyes. Graefes Arch Clin Exp Ophthalmol 1990; 228:90-100.

13 Melamed S, Pei J, Epstein DL. Short-term effect of argon laser trabeculoplasty in monkeys. Arch Ophthalmol 1985; 103:1546-52.

14 Melamed S, Pei J, Epstein DL. Delayed response to argon laser trabeculoplasty in monkeys. Morphological and mor-
phometric analysis. Arch Ophthalmol 1986;104:1078-83.

15 Melamed S, Epstein DL. Alterations of aqueous humour outflow following argon laser trabeculoplasty in monkeys. Br f Ophthalmol 1987; 71:776-8

16 Koss MC, March WF, Nordquist RE, et al. Acute intraocular pressure elevation produced by argon laser trabeculoplasty in the cynomolgus monkey. Arch Ophthalmol 1984;102:1699-703.

17 Alvarado JA. Laser photocoagulation for glaucoma research and therapy. Arch Ophthalmol 1984;102:1604-16.

18 Bylsma SS, Samples JR, Van Buskirk EM. Trabecular cell division after argon laser trabeculoplasty. Arch Ophthalmol 1988;106:544-7.

19 Dueker DK, Norberg M, Johnson DH, et al. Stimulation of cell division by argon and Nd:YAG laser trabeculoplasty in cynomolgus monkeys. Invest Ophthalmol Vis Sci 1990;31: 115-24.

20 Herbort CP, Mermoud A, Schnyder C, et al. Antiinflammatory effect of topical diclofenac sodium
(Voltarene Ophta) after argon laser trabeculoplasty: (Voltarene Ophta) after argon laser trabeculoplasty: preliminary results of a prospective double-b

21 Mermoud A, Pittet N, Herbort CP. Inflammation patterns after laser trabeculoplasty measured with the laser flare meter. Arch Ophthalmol 1992;110:368-70

22 Bergea B. Repeated argon laser trabeculoplasty. Acto Ophthalmol Copenh 1986;64:246-50.

23 Huk B, Garus HJ, Bleckmann H. Anti-inflammatory treatment after argon laser trabeculoplasty. Ophthalmologica 1991;203:24-9.

24 Hugkulstone CE. The effects of different energy levels in argon laser trabeculoplasty. Acta Ophthalmol Copenh 1989; 67:271-4.

25 Hugkulstone CE. Argon laser trabeculoplasty with standard and long duration. Acta Ophthalmol Copenh 1990;68:57981 .

26 Hugkulstone CE. Standard and long duration repeat argon laser trabeculoplasty. Acta Ophthalmol Copenh 1990;68: $575-8$.
27 Bergea B. Intraocular pressure reduction after argon laser rabeculoplasty in open-angle glaucoma. A two-year follow-up. Acta Ophthalmol Copenh 1986;64:401-6.

28 Fink AI, Jordan AJ, Lao PN, et al. Therapeutic limitations of argon laser trabeculoplasty. Br f Ophthalmol 1988;72:263-9.

29 Rouhiainen $H$, Terasvirta $M$. The laser power needed for optimum results in argon laser trabeculoplasty. Acta Ophthalmol Copenh 1986;64:254-7.

30 Rouhiainen H, Terasvirta M, Tuovinen E. Low power argon laser trabeculoplasty. Acta Ophthalmol Copenh 1987;65:6770

31 Rouhiainen HJ, Terasvirta ME, Tuovinen EJ. Laser power and postoperative intraocular pressure increase in argon laser trabeculoplasty. Arch Ophthalmol 1987;105:1352-4.

32 Juhas T, Doci J. Complications of argon laser trabeculoplasty. Cesk Oftalmol 1989;45:111-21.

33 Juhas T. Argon laser trabeculoplasty. Methods, results and complications. Cesk Oftalmol 1990;46:106-15.

34 Weinreb RN, Ruderman J, Juster R, et al. Influence of the number of laser burns administered on the early results of argon laser trabeculoplasty. Am f Ophthalmol 1983;95:28792 .

35 Weinreb $\mathrm{RN}$, Ruderman J, Juster $\mathrm{R}$, et al. Immediate intraocular pressure response to argon laser trabeculoplasty. Am f Ophthalmol 1983;95:279-86.

36 Takenaka Y, Yamamoto T, Shirato S. One-quadrant argon aser trabeculoplasty and its indication. $\mathcal{F p n ~}^{\mathrm{f}}$ Ophthalmol 1987;31:483-8.

37 Richter CU, Shingleton BJ, Bellows AR, et al. Retreatment with argon laser trabeculoplasty. Ophthalmology 1987;94: $1085-9$.

38 Jorizzo PA, Samples JR, Van-Buskirk EM. The effect of repeat argon laser trabeculoplasty. Am $\mathcal{F}$ Ophthalmol 1988; 106:682-5.

39 Brown SV, Thomas JV, Simmons RJ. Laser trabeculoplasty re-treatment. Am f Ophthalmol 1985;99:8-10.

40 Schoenleber DB, Bellows AR, Hutchinson BT. Failed laser trabeculoplasty requiring surgery in open-angle glaucoma. Ophthalmic Surg 1987;18:796-9.

41 Feldman RM, Gross RL, Spaeth G, et al. Risk factors for the development of Tenon's capsule cysts after trabeculectomy. Ophthalmology 1989;96:336-41.

42 Hoskins HD Jr, Migliazzo C. Management of failing filtering blebs with the argon laser. Ophthalmic Surgery 1984;15:731-3.

43 Ophir A, Ticho U. Delayed filtering bleb encapsulation. Ophthalmic Surg 1992;23:38-9.

44 Ophir A. Encapsulated filtering bleb: a selective reviewnew deductions. Eye 1992;6:348-52.

45 Richter CU, Shingleton BJ, Bellows AR, et al. The development of encapsulated filtering blebs. Ophthalmology 1988; 95 9:1163-8.

46 Migdal C, Gregory W, Hitchings R. Long-term functional outcome after early surgery compared with laser and medicine in open-angle glaucoma. Ophthalmology 1994;101: $1651-7$. 